Journal of Sustainable Development of Transport and Logistics

journal home page: https://jsdtl.sciview.net

Yuen, S. S. M. (2019). Public transport services in Hong Kong: A voice from Hong Kong citizen (Policy paper). Journal of Sustainable Development of Transport and Logistics, 4(2), 22-31. doi:10.14254/jsdtl.2019.4-2.2.

\title{
Public transport services in Hong Kong: A voice from Hong Kong citizen (Policy paper)
}

\section{Simon S.M. Yuen}

The Hong Kong Polytechnic University, Hung Hom, Hong Kong, China College of Professional and Continuing Education (CPCE) spsmyuen@speed-polyu.edu.hk

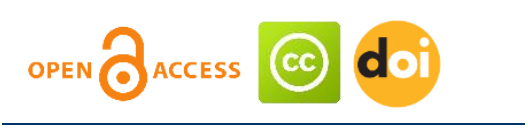

Article history:

Received: July 25, 2019 1st Revision: August 10, 2019 Accepted: November 12, 2019

\section{DOI:}

10.14254/jsdtl.2019.4-2.2

\begin{abstract}
Hong Kong is a city with a diversified public transport system. However, the number of private cars has increased abnormally, especially the completion of private housings in the New Territories and North Lantau, due to the daily work of the urban areas or personal needs. The number of citizens of private cars has increased significantly. In recent years, the problem of "frequent and severe congestion" has resulted in the saturation of the more timely railways. The main reason is that the roads in the existing busy areas cannot meet the large number of private cars, and the major roads in the New Territories of Hong Kong and Kowloon have been subject to "frequent and severe congestion". The Government's solution to the problem is to build roads and railways only. In recent years, many new roads and railways, the congestion of old roads and highways have not been improved. Railways cannot change the private car owners to switch to public transport habits, "but increased", what is the main reason? Where roads and railways solve problems, this study agrees that denser areas without rail services are necessary to build or extend existing rail routes. But what is the need to build a new railway to relieve the existing railway saturation? We use the railway but not others? Is railway extension is one of the cause for traffic congestion? In recent years, the government has recognized that private cars are the main source of traffic congestion in Hong Kong. Government indicated that it planned to introduce another electronic road toll and increase private license plate or registration tax. Hope that this report will help us understand the problems we are facing now and discuss how we can resolve them so as to come up with better solutions.
\end{abstract}

Keywords: public transport, railway, private car, Hong Kong 


\section{Background}

In the early 1960s, the economy of Hong Kong began to grow at a rapid pace, with the manufacturing sector leading the economy of Hong Kong at that time, meanwhile, the population had risen continuously. At that time, the population of Hong Kong was mainly in the Kowloon Peninsula and the northern shore of Hong Kong Island, while the factory areas were concentrated in Kwun Tong and Cheung Sha Wan. The urban area was very crowded.

Due to the persistent political instability in the Mainland, a large influx of people is expected to emerge in Hong Kong, and the post-war baby boomers were becoming adults. The Government expects the population to continue its rapid expansion. In order to solve the problem of land supply for industrial sustainable development, and to disperse the overcrowded urban population, the Government decided to develop the satellite city (now known as the new town).

The Government is developing new towns with the intention of making the residents in the district "self-sufficient", namely the establishment of industrial areas, markets, schools and other recreational areas in the district for employment, schooling and recreation, and predict that the population structure almost. The first developments were in Tsuen Wan and Kwai Chung. In the 1970s, the Government started to develop Sha Tin and Tuen Mun districts, and later Tai Po, Yuen Long, Fanling, Sheung Shui, Ma On Shan, Tseung Kwan O, Tin Shui Wai and Tung Chung in the New Territories, and Chai Wan and Southern District on Hong Kong Island.

Similarly, there are industrial sites attached to various districts such as Shek Mun in Shatin and a large industrial area in the west of Tuen Mun River, Tai Po Industrial Estate, Tung Tau Industrial Estate in Yuen Long, Chai Wan in Eastern District and Wong Chuk Hang in Southern District.

New towns failing to be "self-sufficient and balanced"

But the subsequent development of new towns, the Government's "balanced development, selfsufficiency" cannot be fully implemented. First, when the Government develops new towns, it only focuses on the development of public housing estates. The industrial districts in various districts fail to develop simultaneously. As a result, the supply of jobs in the districts is inadequate. Many residents, in order to maintain their original treatment and benefits, the original post in the urban area. And moved in, and more young couples, community, education, support is very strong,

External factors

In the 1980s, with the introduction of "reform and opening up" in the Mainland, the industrial development of Hong Kong was greatly affected by the low cost (land use and labor) to attract Hong Kong businessmen to invest in the north. A large number of Hong Kong businessmen went north to open factories, Slowed down the new development of the industrial area continued lack of sufficient jobs to the local residents employment. Hong Kong began to turn into a financial center and other service industries. The citizens were slowly concentrating on working in the financial and commercial districts of Yau Tsim Mong and Central District. (Television Broadcast Limited, 1995)

As a result, the current pattern of transport (passenger transport) of Hong Kong has generally not taken shape since the 1980s, that is, nearly half of the office workers have to travel long distances to work in the urban areas on a daily basis. There are millions of people who work across multiple districts every day and the demand for public transport is high.

At present, although there are nearly 10 railway routes and nearly 6000 franchised buses, and a large number of non-franchised buses and minibuses, the overall provision of such services seems to be only possible. First, the road conditions, an overview of the daily peak hours, the new towns are still smooth road. But every time the highway, especially when the tunnel and into the urban area, the time of journey are increased by double. Despite the completion of the newly completed roads and tunnels in the recent 10 years, the road surface after entering the urban area is limited and there is no room for further widening. Even if the operators still have the ability to increase the frequency of trips, the urban roads were already saturated during the peak hours, almost cannot accommodate the new routes / trips. For railway systems, the various routes in recent years has begun in the new towns of the road early saturation, often there are still a number of stations to enter the urban section, has appeared in the public waiting on the platform 3 or 4 trains to successfully boarded. 


\section{Traffic problems facing the five major regions of Hong Kong}

Hong Kong Island

* Landway:

o Most of the roads in the morning from North Point to Causeway Bay are slow (Eastern Corridor, Gloucester Road and Harcourt Road)

o Evening peak hours, Gloucester Road eastbound carriageway, once long to Sheung Tak Center. The general dragon tail will be in Central

o Aberdeen tunnels are often "inverted" due to the number of vehicles in the Crossing Harbour Tunnel

o The Eastern Harbour Tunnel traffic congestion towards Kowloon East is North Point during the evening peak hours

* RAILWAY:

- Admiralty Interchange, the trains towards Tsuen Wan and Chai Wan in the evening peak hours, an average of 2-3 trains

o North Point Interchange, the trains towards Kennedy Town in the morning peak hours, an average of 2-3 trains

Kowloon East

* Landway:

o Began to bear less than the pace of rapid development. The queue towards Kwun Tong in the morning peak hours, often in the Diamond Hill has been there

0 During the evening peak hours, Kwun Tong Road is often congested. Many vehicles are trapped. Frequent departures of bus routes

o In the early morning hours of the Eastern Harbor Tunnel, the car is often seen in the Sceneway Garden

* Railway:

Kowloon West

o Tseung Kwan 0 line capacity of more than 100\% (Wen Wei Po, 2014a)

* Landway:

o The traffic queues at the entrance of Kowloon of the Crossing Harbour Tunnel, are extended east, north and west during most of the day. East to the Kai Tak Tunnel, west to Yau Ma Tei, north to Ho Man Tin Princess Road

o Nathan Road and Mong Kok Road junction

Railway:

o Tung Chung Line towards Hong Kong Station, to the Olympic station has been saturated

- Kowloon Tong Interchange (East Rail Line to Kwun Tong Line), an average waiting for 2-3 trains

o Tsuen Wan line capacity of 98\% (Wen Wei Po, 2014a

New Territories East

* Landway:

o In the morning peak hours, Lion Rock Tunnel Road to the direction of Kowloon, long queues to City One

o Tai Po Road to Kowloon / Tsuen Wan, long queues near to Sha Tin Racecourse

* Railway:

- East Rail Line Tai Wai Station to Hung Hom direction, the average waiting for 3 buses to get on the train. The overall capacity of 100\% (Wen Wei Po, 2014b)

New Territories West (Including Outlying Islands)

* Landway:

o In the morning, there was a traffic jam between Tuen Mun Road, uphill position is often slow

o Only the Tsing Ma Bridge and the Kap Shui Mun Bridge are accessible from and out of Lantau. There was no complete package and information release in the event of an accident.

* Railway: 
o West Rail line carrying capacity of $99 \%$, only recently began to add car train (Wen Wei Po, 2014b)

\section{Territory-wide issues}

\section{(I) Railway}

$>$ Is the "rail-based" policy the most needed?

In the Railway Development Strategy 2000 published by the Government in 2000, the transport policy of "railway as the backbone" was put forward. Buses were the supporting roles. With the completion of the new railway extension, the bus companies will face a significant restructuring. However, the reorganization of the bus is not fully deployed in other demand on the road. Some of the public have continued to "bake" crowded MTR because there is no choice.

According to the documents submitted to the Legislative Council by the Transport Authority in 2014, the East Rail Line and the Tseung Kwan 0 line are the most saturated. Other routes are close to $100 \%$. Under such circumstances, does the "rail-based" transport policies need to be reviewed and whether the public needs the most?

Table 1: The carrying capacity and loading of MTR railway lines during morning peak hours on the busiest sections in 2013 (LC, 2015)

\begin{tabular}{|l|c|l|}
\hline \multicolumn{1}{|c|}{ Line } & $\begin{array}{c}\text { Loading } \\
\text { (4 people per sq m) }\end{array}$ & \multicolumn{1}{c|}{ Critical Link } \\
\hline East Rail Line & $100 \%$ & Tai Wai to Kowloon Tong \\
\hline West Rail Line & $99 \%$ & Kam Sheung Road to Tsuen Wan West \\
\hline Ma On Shan Line & $80 \%$ & Che Kung Temple to Tai Wai \\
\hline Tseung Kwan O Line & $100.6 \%$ & Yau Tong to Quarry Bay \\
\hline Island Line & $93 \%$ & Tin Hau to Causeway Bay \\
\hline Kwun Tong Line & $94 \%$ & Shek Kip Mei to Prince Edward \\
\hline Tsuen Wan Line & $98 \%$ & Tsim Sha Tsui to Admiralty \\
\hline Disneyland Resort :Line & $35 \%$ & Sunny Bay to Disneyland Resort \\
\hline Tung Chung Line & $84 \%$ & Olympic to Kowloon \\
\hline Airport Express & $54 \%$ & Airport to Tsing Yi \\
\hline
\end{tabular}

$>$ Is it appropriate to build a railway to divert the saturation of another railway line?

This study reveals that the construction of the railway will help ease the traffic congestion on the old busy road, but not every plug. The Government must understand the real causes of the traffic jam, find out the effective solution first, and finally study the feasibility of building a railway. It takes 8 to 10 years or more to build a railway. The Government should tackle the traffic congestion problem with policies or existing technology, which is more cost-effective than the 8 to 10 -year construction of railways. railways

$>$ The views of the public on public transport services and the reasons for taking the

In response to this study, this study made a special trip to visit the public's needs / views on the existing public transport services and the reasons for taking the railways. After investigation, we found that $95 \%$ of the respondents did not agree with the existing "railway-based" policy. It has also been mentioned above that the current traffic situation is more serious than before and has occurred in every district, particularly in some fast-growing areas, and congestion during non-peak hours.

\section{(II) Land-Way}

$>$ Causes of severe traffic congestion on main roads of hong kong and kowloon

Today, Hong Kong can be described as a traffic jam city. In congested areas (such as Central, Wan Chai and Yau Tsim Mong), traffic congestion will occur daily. But in recent years has been extended to all districts or roads, such as Kowloon East, Kowloon City, Lung Cheung Road, Tolo Highway and Tuen Mun Highway, they have reached a serious level. After our in-depth study and analysis, the culprit is private cars, the streets of the park vehicles, restricted area is not comprehensive and tunnel charges vary. 
First of all, private cars constitute more than half of the total number of road vehicles in Hong Kong and the number of them continues to increase significantly. If there is no control as soon as possible, the traffic congestion in Hong Kong will only continue to deteriorate. In recent years, there will be serious congestion in all major districts. Also, it has spread to the Kowloon East area and has become more serious.

\begin{tabular}{|} 
Table 2: Registration and Deregistration of Private Cars in the past 6 years (Transport Department, 2016) \\
\hline Year & Gross First Registration & Deregistration & Net First Registration* \\
\hline 2011 & 44569 & 3470 & 41119 \\
\hline 2012 & 44983 & 2216 & 42767 \\
\hline 2013 & 45382 & 1274 & 44108 \\
\hline 2014 & 46636 & 398 & 46238 \\
\hline 2015 & 50322 & 289 & 50033 \\
\hline $\begin{array}{c}2016 \\
\text { (Jan-Aug) }\end{array}$ & 26292 & 273 & 26019 \\
\hline
\end{tabular}

*Net first registration refers to the number of first registered private cars discounting those deregistered

$>$ What is the reason for the rising number of private cars?

This is mainly due to the completion and occupation of a large number of housing estates in the New Territories, particularly those located in Yuen Long Kam Tin, Shap Pat Heung, Tai Po East, North District and Tolo Harbour. There are a large number of middle-class or high-wage people living in these estates daily. They drive from the New Territories to work in the urban areas of Hong Kong and Kowloon. The main reason is that the taxi service has failed to meet their needs. It is very difficult to get taxis or call taxis from the New Territories to the urban areas, and most of them are taxi drivers in the New Territories who cannot get out of the urban area. As middle-class and high-income group, say so-call "time is money", it is imperative to purchase private cars.

This study visited a middle-class friend living in Mont Vert, Tai Po. He needs to go to Shek Mun industrial area in Sha Tin every day. Most of the taxis passing through his residence are New Territories taxis. While Shek Mun in Sha Tin is an "urban area" in which the New Territories taxis are not allowed to enter. In the morning, finding urban taxis have been very difficult, even if the private car spending, but unfortunately have to buy a private car. These examples are happening throughout the New Territories and the Government needs to pay more attention to such regulation.

$>$ Does the government increase the number of private license plates to control fees?

As a private car user / owner, I believe we have a certain capacity to support the majority of the cost of private cars, such as parking fees, fuel costs, maintenance, licensing fees, tolls and so on. Therefore, this study views that the increase in private license plate fees alone will not affect the desire to buy a private car, and help to control the number of private cars.

Residential residents living far away, inadequate public transport services, driving private cars is so popular. If government wants to change the public's switch to public transport services, it must study and deal with it at full speed rather than relying solely on the increase in license fees. Otherwise, the traffic flow of most roads in Hong Kong will continue to multiply over the next five years. Private cars are more likely to account for $80 \%$ of all vehicular traffic in Hong Kong. More roads will be more congested.

- Impact on Cross- Harbour tunnels fees and uneven traffic flow

For tunnels, the tolls of the three cross-harbor tunnels are different. Since the opening of the Western Harbour Tunnel, the entrance of the Western Harbor Crossing has remained unimpeded at all times. On the contrary, the Cross Harbour Tunnel is most congested at any time because the Western Harbour Tunnel and the Eastern Harbor Tunnel are more expensive and more than twice as many as the Western Harbour Tunnel. Many vehicles use the Cross Harbour Tunnel so as to cause traffic congestion in the vicinity and seriously affect the busy traffic.

Since the opening of the Western Harbour Tunnel, there has been only three days of traffic congestion. The main reason for this is that the three days are free of charge and the Cross Harbour Tunnel and Eastern Harbor Tunnel are very smooth. The Cross Harbour Tunnel continues to be congested with signs of deterioration. Although the operation of the Eastern Harbour Tunnel expired 
on 7 August 2016, it was not play a significant role in relieving the congestion of the Cross Harbour Tunnel because of different areas and targets. The government should try to solve the problem of tolls at three cross-harbor tunnels as soon as possible. If the number of private cars continues to increase, the public cannot tolerate the expiry of the right to operate the Western Harbour Tunnel by 2023.

The table below shows the number and total flow of private cars in the three cross-harbor tunnels.

Table 3: Cross Harbour Tunnel
\begin{tabular}{|c|c|c|c|}
\hline Year & Private Cars & All Vehicles & $\begin{array}{c}\text { Private cars as a percentage of all } \\
\text { vehicles }\end{array}$ \\
\hline 2008 & 15777686 & 44375838 & $35.55 \%$ \\
\hline 2009 & 15922291 & 44318966 & $35.93 \%$ \\
\hline 2010 & 15693803 & 44131405 & $35.56 \%$ \\
\hline 2011 & 15915679 & 43998983 & $36.17 \%$ \\
\hline 2012 & 15987135 & 43265924 & $36.95 \%$ \\
\hline 2013 & 16138901 & 42615079 & $37.87 \%$ \\
\hline 2014 & 16409196 & 42044261 & $39.03 \%$ \\
\hline 2015 & 17014255 & 42238498 & $40.28 \%$ \\
\hline 2016 & 11748262 & 28012373 & $41.94 \%$ \\
\hline (Jan - Aug) & & & \\
\hline
\end{tabular}

Table 4: Eastern Harbour Tunnel
\begin{tabular}{|c|c|c|c|}
\hline Year & Private Cars & All Vehicles & Private cars as a percentage of all vehicles \\
\hline 2008 & 12449745 & 23137619 & $53.81 \%$ \\
\hline 2009 & 12570378 & 22990195 & $54.68 \%$ \\
\hline 2010 & 13342435 & 24648289 & $54.13 \%$ \\
\hline 2011 & 13649231 & 25374790 & $53.79 \%$ \\
\hline 2012 & 13990321 & 25883548 & $54.05 \%$ \\
\hline 2013 & 14264788 & 26317796 & $54.20 \%$ \\
\hline 2014 & 14592003 & 26657699 & $54.74 \%$ \\
\hline 2015 & 15164595 & 27546065 & $55.05 \%$ \\
\hline 2016 & 10214855 & 18256740 & $55.95 \%$ \\
(Jan -Aug) & & & \\
\hline
\end{tabular}

Table 5: Western Harbour Tunnel
\begin{tabular}{|c|c|c|c|}
\hline Year & Private Cars & All Vehicles & Private cars as a percentage of all vehicles \\
\hline 2008 & 8812860 & 17473527 & $50.44 \%$ \\
\hline 2009 & 8940492 & 17600924 & $50.80 \%$ \\
\hline 2010 & 9692213 & 19556854 & $49.56 \%$ \\
\hline 2011 & 10082071 & 20786819 & $48.50 \%$ \\
\hline 2012 & 10771675 & 22125482 & $48.68 \%$ \\
\hline 2013 & 10973605 & 22614125 & $48.53 \%$ \\
\hline 2014 & 11112576 & 23006349 & $48.30 \%$ \\
\hline 2015 & 11760455 & 23843658 & $49.32 \%$ \\
\hline 2016 & 8044771 & 16010885 & $50.25 \%$ \\
(Jan - Jul) & & & \\
\hline
\end{tabular}

What are the reasons for the bus service problem?

The impact of the traffic jam is very bleak on the prospects of non-railway public transport such as buses, minibuses and taxis. This is mainly due to the serious impact on their daily operations. This has resulted in a significant increase in travel time. This has caused the public to lose their budgets and change the railways. As a result, the fare income has been reduced, further aggravating the operators.

We do not think that traffic congestion can be resolved in short run. If there is a traffic accident on any street in a busy area, the traffic in the whole area and the adjacent area will be almost paralyzed. The frequency of trips and travel time of all land-based public transport will be seriously affected. This will result in serious trips. Public may have been waiting for more than an hour at the station and still have no bus or minibus. 
In the past, the Transport Department had blamed the franchised buses for traffic congestion and poor roadside air quality. How can the number of franchised buses in Hong Kong be just over 6,000 and the number of private cars close to 600,000 will seriously affect the traffic congestion in Hong Kong?

In addition to the large number of private cars, many private car drivers do not abide by the traffic rules (for example, unintentional tangential traffic accidents, illegal parking in busy streets and streets, parking in restricted areas, speeding and red lights leading to traffic accidents). Most of the vehicles use a less expensive Crossing Harbour Tunnel to cross the harbour, which is the main cause of traffic congestion, and will block the bus and heavy vehicles to walk. It may be unfair to the franchised bus operators that the bus which could have been used as a railway to ease the traffic will be more attractive than the traffic jam because of the congestion.

\section{(III) Waterway}

$>$ Reasons for continuous operating difficulties for ferries?

Ferry to accompany many Hong Kong people grow, from one shore to another shore, once the public's most popular public transport for crossing harbour, is now the backbone of the islands. With the continuous development of transport and infrastructures, the distance between the ferry terminal and the city center is widening. The number of cross-harbor routes between Hong Kong Island and Kowloon has been reduced from more than 20 to only 7, which is expected to continue to shrink in the future. While the majority of the remaining routes recorded a loss, and a break-even between Cheung Chau and Yung Shue Wan on Lamma Island, which had a relatively high passenger flow rate.

Due to reclamation, the terminal continued to move, moving further and further, coupled with global warming, the weather warmer year by year, up to 37 degrees in summer, the public walk to the pier is very hard. Therefore, the passenger will prefer to ride other more comfortable means of transport, the ferry so "not worth the candle."

Apart from Star Ferry Piers in Tsim Sha Tsui and Central, which are located at high pedestrian flow, perfect docking facilities and ancillary facilities, most of the terminals are far away from the pedestrian flow and far away from the real destination, only adjacent to a certain housing estates / estates. More pier just adjacent to the factory area, other times sparsely populated.

$>$ Insufficient operational and government support

As a result, the decline in ferry passengers has resulted in a substantial reduction in revenue, with the greatest responsibility being the Government. After the relocation of the pier, the Government has only built a terminal for the ferry company. Other measures to help and remedy the ferry operation are even worse. As a matter of fact, apart from supporting the role of the Government, the ferry seems to feel that the Government's message to the public is "dispensable".

On the street, apart from bus stops and street nameplates, almost all of the Government's pedestrian signs teach people how to walk to nearby MTR stations, but the signboards for walking to ferry terminals are near zero.

\section{- Is the ferry not benefiting from Hong Kong's economic development?}

The continuous construction and development of the Government has allowed the expansion of public transport on land and the increase in the number of passengers and the increase in revenue. On the contrary, most of the ferry did not have any growth, and further decline in passenger volume. The newly completed facilities in Hong Kong have not benefited from the expansion of their patronage and territory. The operating environment has worsened.

Since the Kai Tak cruise terminal was opened in 2013 and there is a serious lack of traffic and its location is close to the Kwun Tong Ferry Terminal, why is it only a symbolic way to operate holiday buses and regular green minibuses? This shows that the facilities are not reserved for ferry.

Moreover, Disneyland Resort has been in operation for 11 years. To enable it, the Government has completed the construction of two Disneyland Resort ferry terminals for over 11 years with a total of $\$ 160$ million. However, no ferry service has been provided. The government planned to operate a ferry service from Disneyland Resort to Central. However, because the MTR Disneyland Resort line was more attractive than the ferry, and the ferry company did not consider the profit to be high, no one bid.

Our study reflects that the Hong Kong ferry service has not benefited from the economic development of Hong Kong over the years, nor is it possible to expand the ferry in the light of 
development and bring about serious business development surroundings. The ferry is a public transport which has witnessed the growth of Hong Kong and has a long history. It is a cheaper and punctual choice for the public. Therefore, the Government should not ignore its role.

Besides, the early closure of the Lantau Link caused a lot of embarrassment to the people of the airport and Lantau Island. After the news was issued, the Government was very slow in finding coordination of sea transport and even instructed the public to go to the airport or Tung Chung method. It was more than an hour and a half before the guidelines were issued. This shows the government mindset: the only "rail or land" attitude, it focuses on the affected area of the MTR Airport Express Line and not to pay attention to the situation in the territory between Tung Chung and the airport. The function of the ferry is thus ineffective to play.

\section{Recommendations}

\subsection{From the fundamental}

Major problems: The number of private cars is very high, and that the tolls of the three crossharbor tunnels are not the same, resulting in varying degrees of traffic congestion. Therefore, this study recommended that we must start from the fundamental to solve existing problems, listed as follows:

I. Set the maximum number of private cars in Hong Kong. If the number to the designated target, should be prohibited licensing, or the implementation of odd and even number of the private car plate driving days to encourage the public to use public transport

II. Restriction of private cars entering busy areas or restricting private cars from using the Crossing Harbour Tunnel during peak hours to relieve traffic congestion in the Crossing Harbour Tunnel and adjacent areas and roads

III. Enhancement of illegal parking of streets in busy areas to facilitate smooth road conditions in busy areas and to facilitate emergency vehicles to handling of incidents at the scene rapidly

IV. Enhance public transport services in the New Territories, increase the number of taxi licenses and increase the use of technology (i.e. APPs) to call taxi or bus services to reduce public use of private cars and improve road air quality.

V. Review taxi policy as soon as possible, such as increasing the number of drop-off points in the New Territories urban areas or considering merging the New Territories and urban taxis

VI. To review the tolls of the tunnels, to make every effort and to make the same tolls of the three cross-harbor tunnels (even free of charge) to relieve the traffic overload of the Crossing Harbour Tunnel. A comprehensive review of the toll collection of the Tai Lam Tunnel to enable the toll collection to attract more vehicles will help solve the traffic congestion problem in Tuen Mun Road, Fanling Highway and Tolo Highway

\subsection{Re-examine the role of existing transport systems}

Railway is becoming increasingly saturated; the land transport system has also reduced the attractiveness of the public because of traffic congestion, resulting in a decline in revenue. The ferry has been suffering from long-term losses due to inadequate publicity, directives and ancillary facilities and a "closed down" crisis. Therefore, in terms of policy, the Government needs to re-examine the existing role of various modes of public transport. So that they can balance development and complement each other. Our study recommended that:

I. Re-examine the "rail-based" transport policy, so that other non-railway traffic will be moderately competitive and relieve the increasingly saturated railway system

II. Franchised buses continue to make up for the shortage of railways, especially in areas where railways are not available. Connecting railways / shuttle bus routes, interchange discounts should be provided with the inter-district / urban routes, to strengthen the district network 
III. If the number of franchised bus routes is extremely low and the green minibus has fully met the passenger demand, it is proposed that the concerned route be operated by a green minibus and the fares should be close to the canceled bus routes

IV. The Government should study how to enhance the number of green minibus passengers and improve the operating environment. Such as continuing to attract more red minibus to green minibuses and increase the minibus capacity to 20 seats...etc.

V. Non-franchised public buses are shortfalls in the franchised bus routes and are mainly subsidized franchised bus services

\section{Conclusion}

Regardless of road traffic services, logistics, and even emergency services, are seriously affected because of traffic congestion problems, but also signs of deterioration in the long run will affect the economy. This is not a matter of immediate solution to the construction of roads or railways alone, as it will take 8-10 years. In fact, the Government can use policies and techniques to control and improve traffic. Although the existing government policy is support railways (construction and network extension); But, according to the actual situation, will railways continue to be constructed indefinitely? Development will always end. Hong Kong's traffic is not just the railway, there are other diversified modes of transport.

The question is whether the government and related parties have properly coordinated, their efforts to take advantage of the various modes of transport. Therefore, if the Government can achieve the above-mentioned measures and successfully tackle the problem of traffic congestion, it will use less resource to enhance effective and efficient public transport services.

In the next few years, a number of transport infrastructure projects will be completed. MTR Kwun Tong Line and the South Island Line were operated in late 2016. It is expected that the opening of the new branch lines will completely change the traffic in these areas. Most of the existing bus and minibus routes will face reorganization, such as shortening routes, service hours and cancellations.

More resources can be properly deployed and will be put in some of the needs of the route, so that transport agencies can play its advantages, complementary deficiencies, to provide more convenient public transport services in these areas.

\section{Funding}

IDEA4HK - Hong Kong Economic and Logistics Research Centre and PTTT(HK).

\section{Acknowledgement}

This study was carried out thanks to the support of the IDEA4HK - Hong Kong Economic and Logistics Research Centre and PTTT(HK).

\section{Citation information}

Yuen, S. S. M. (2019). Public transport services in Hong Kong: A voice from Hong Kong citizen (Policy paper). Journal of Sustainable Development of Transport and Logistics, 4(2), 22-31. doi:10.14254/jsdtl.2019.4-2.2. 


\section{References}

LC (2015), Legislative Council Panel on Transport Subcommittee on Matters Relating to Railways Capacity and Loading of MTR Trains [LC Paper No: CB (1)980/13-14(03)]. Transport and Housing Bureau.

Television Broadcasts Limited (1995), 星期五檔案-屯門塞車 (13 October 1995).

Transport Department (2016), Monthly Traffic and Transport Digest, August 2016, Transport Department.

Wen Wei Po (2014a), 羅繼盛：錯估載客企到爆 港鐵研拆發 (26 February 2014).

Wen Wei Po (2014b), 文森：東鐵載客量達100\% 促研「早晨特惠」(1 March 2014).

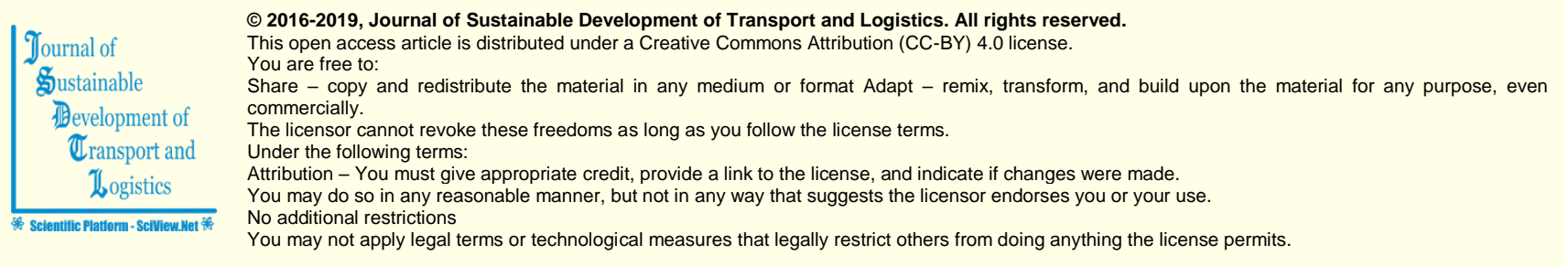

Journal of Sustainable Development of Transport and Logistics (ISSN: 2520-2979) is published by Scientific Publishing House "CSR", Poland, EU and Scientific Publishing House "SciView", Poland, EU

Publishing with JSDTL ensures:

- Immediate, universal access to your article on publication

- High visibility and discoverability via the JSDTL website

- Rapid publication

- Guaranteed legacy preservation of your article

- Discounts and waivers for authors in developing regions

Submit your manuscript to a JSDTL at https://jsdtl.sciview.net/ or submit.jsdt|@sciview.net 